\title{
Öğretmen-Öğrenci İlişkisinin Öğrencilerin Duygu Düzenleme ve Duygu İfade Etme Becerilerine Etkisinin İncelenmesi
}

\author{
DOI: $10.26466 /$ opus.839272 \\ $*$ \\ Belgin Liman * \\ * Dr. Öğr. Üyesi, Niğde Ömer Halisdemir Üniversitesi, Çocuk Gelişimi, Niğde/Türkiye \\ E-Posta: yliman@mynet.com.tr ORCID: 0000-0003-4965-2379
}

Öz

Araştırmanın amacı, 5-6 yaş çocuklarının öğretmenleri ile olan ilişkilerinin, duygu düzenleme ve duygu ifade etme becerileri üzerindeki yordayıcı etkisini ortaya koymaktır. Araştırmanın çalışma grubunu basit rastgele örnekleme yöntemi ile seçilen 2019-2020 eğitim öğretim yılında İç Anadolu Bölgesinin bir ilinde MEB'e bağlı bağ̆ımsı anaokullarına ve anasınfflarına devam eden 146 çocuk ile 22 okul öncesi öğretmeni oluşturmaktadır. Araştırmada Kişisel Bilgi Formu, Duygu Düzenleme Ölçeği, Duygu İfade Etme Testi ve Öğretmen-Öğrenci İlişki Ölçeği kullanılmıştır. Verilerin analizinde çok değiş̧kenli regresyon analizi kullanılmıştır. Sonuç; öğretmen-öğrenci ilişkisinin çatışma alt boyutu ve cinsiyet değişkeni değiş̧kenlik/olumsuzluk puanların anlamlı düzeyde yordamaktadır. Öğretmen-öğrenci ilişkisinin çatışma boyutu değişkenlik/olumsuzluk alt boyutunda pozitif yönlü; cinsiyet değişkeni ise negatif yönlü bir ilişkiye sahiptir. Duygu düzenleme puanlar üzerindeki etkileri bakımından en güçlü ve anlaml yordayıcının çatışma, ikinci güçlü ve anlamlı yordayıcının cinsiyet, üçüncü güçlü ve anlaml yordayıcının ise yakınlık değişkeni olduğu saptanmıştır. Ö̆̆gretmen-öğrenci ilişkisinin çatışma ve yakınlı boyutu duygu düzenleme ve duygu ifade etme alt boyutunda pozitif yönlü yordayıcı etkiye sahiptir.

Anahtar Kelimeler: $\quad$ Okul öncesi, Öğretmen-öğrenci ilişkisi, Duygu düzenleme, Duygu ifade etme. 


\title{
Examination of the Effect of Teacher-Student Relationship on Students Emotion Regulation and Emotion Expression Skills
}

\begin{abstract}
This study explored the predictive effect of 5-6 years old children's relationships with their teachers on their emotion regulation and emotion expression skills. Selected by simple random sampling method, the study group was made up of 146 children and 22 kindergarten teachers who had been attending and working at independent kindergartens and kindergartens affiliated with the Ministry of National Education in a city in the Central Anatolia Region during the 2019-2020 academic year. The Personal Information Form, Emotion Regulation Q-Scale, Emotion Expression Scale and Teacher-Student Relationship Scale were used in the study. Multivariate regression analysis was performed in the analysis of the study data. According to the study results, the conflict dimension of the teacherstudent relationship and the gender variable significantly predicted the variability/negativity scores. In the variability/negativity sub-dimension, the conflict dimension of teacher-student relationship had positive relationship, whereas the gender variable had negative relationship. In terms of its effects on emotion regulation scores, the strongest and most significant predictor was conflict. This was followed by gender and closeness, respectively. Finally, the conflict and closeness dimension of the teacherstudent relationship had a positive predictive effect in the emotion regulation and emotion expression sub-dimension.
\end{abstract}

Keywords: Preschool, Teacher-student relationship, Emotion regulation, Emotion expression. 


\section{Giriş}

Duygular, durumlara ve yaşantılara ilişkin bir tepki olarak ortaya çıar. Duygusal gelişimlerine paralel olarak çocuklar çeşitli olumlu ve olumsuz duyguları deneyimlemektedir. Çocukların yaşadıkları olumlu ya da olumsuz duygularını ifade etme şekilleri yaşantılarla bağlantılı olarak farklılaşabilmektedir. Duygu ifade etme, çocukların duygularını çevresindekilere aktarma şeklidir (Denham, 2006) ve duygu durumlarının iletilmesinde yüz, ses ve diğer beden hareketlerinin kullanmasıyla gerçekleştirilen davranışlardır (Chaplin, 2015). Duyguların ifade edilmesi sırasında ortaya çıkan duygusal tepkilerin, davranışları etkilemesi ise duygu düzenleme olarak tanımlanmaktadır (Bridges, Denhama ve Ganiban, 2004). Duygu düzenleme, çocukların yaşadığ 1 ve ifade ettiği duyguların kontrol sistemidir (Cole, Martin ve Dennis, 2004). Çocuklar ilkokul deneyimleri sırasında duygularını düzenlemeyi gerektirenbirçok durumla karşılaşmaktadır (Denham, 2006) ve bu durum davranışsal, akademik ve sosyal alanlardaki becerilerinde etkilidir. Başarılı bir duygu düzenleme için çocukların kişiler arası ilişkiler ve olumlu okul deneyimleri için olumlu duygusal mesajlar anlamayı ve göndermeyi öğrenmeleri gerekmektedir (Halberstadt, Denham and Dunsmore, 2001). Çocukların olumsuz duygularını sosyal bağlamda uygun olmayan şekilde ifade etmeleri, çevreleri ile olan uyumlarını bozabileceği gibi çeşitli davranış problemlerine neden olabilmektedir (Durmuşoğlu-Saltalı, 2010; Eisenberg vd., 2003; KayhanAktürk, 2015; Helmsen, Koglin ve Petermann, 2012; Miller vd., 2006; Romanchych, 2014; Shaw, 2006).

Çocuğun doğduğu andan itibaren duyguları düzenleme becerileri de dahil olmak üzere tüm gelişim alanları üzerinde, ailenin etkileri büyüktür (Duncan ve Brooks-Gunn, 2000; Linver, Brooks-Gunn ve Kohen, 2002; Morris, Silk, Steinberg, Myers ve Robinson, 2007). Ebeveyn ile çocuk arasında kurulan bağ çocuğun sağlıklı gelişimi ve toplumsal uyumu açısından önemlidir. Okul öncesi dönemde çocuk için anne babadan sonra ilişki kurduğu ve güvenli bir bağ oluşturduğu kişilerden bir öğretmendir (Koles, O'Connor ve McCartney, 2009; Zhang, 2011; Zhang ve Nurmi, 2012). Aile ve çocuk arasındaki bağlılık çocuğun duygusal gelişimi açısından nasıl büyük bir öneme sahipse öğretmen ve 
çocuk arasındaki karşılıklı güvene dayalı ilişkide çocukların duygusal gelişimi için vazgeçilmez öneme sahiptir. Öğretmen-öğrenci ilişkisi iletişimden çatışmaya, yakınlıktan bağımsızlığa kadar birçok durumu içermektedir. Okul sürecinde öğretmen ve öğrenci inançlarının, tutumlarının, davranışlarının birbirleriyle etkileşimleri sonucu şekillenmektedir. Bazı öğretmen-öğrenci ilişkileri yakınlık ve duygusallık içerirken, bazıları ise çatışma ve gerilim içerebilmektedir (Pianta ve Stuhlman, 2004). Öğretmenleriyle güçlü ve destekleyici ilişkiler kurmak, çocukların okul ortamında kendilerini daha güvenli ve yetenekli hissetmelerine, akranlarıyla daha olumlu ilişkiler kurmalarına ve akademik açıdan olumlu kazanımlar elde etmelerine olanak sağlamaktadır (Birch ve Ladd, 1997; Curby, Rimm-Kaufman ve Pointz, 2009; Hamre ve Pianta, 2006; Peisner-Feinberg vd., 2001; Wentzel, 2009). Öğretmenin destek davranışları ve düşük çatışma durumları yüksek akademik başarıyla ilişkilendirilmekte (Hamre ve Pianta, 2001; Ly, Zhou, Chu ve Chen, 2012; Silver, Measelle, Armstrong ve Essex, 2005) olumsuz ilişkilerin, çocuğun gelişimini olumsuz yönde etkilediği belirtilmektedir (Doumen, Verschueren, Buyse, Germeijs, Luyckx ve Soenens, 2008; Howes, 2000; Pianta ve Nimetz, 1991). Öğretmenleriyle güvenli bağlar geliştiren okul öncesi çocuklarının düzensiz öfke ve davranış problemleri gösterme olasılıklarının daha düşük, okulda olumlu duygular gösterme olasılıklarının daha yüksek olduğu vurgulanmaktadır (DeMulder, Denham ve Schmidt, 2000; MitchellCopeland, Denham ve DeMulder, 1997). Öğretmen-öğrenci ilişkisinin kalitesi arttıkça, problem davranışlara sahip öğrencilerin sosyal, davranışsal yönden ve uyum açısından daha olumlu yönde değiştiği belirlenmiştir (Decker, Dona ve Christenson, 2007). Öğretmen-öğrenci arasındaki ilişki sadece öğrencinin değil öğretmenin de duygusal-sosyal durumunu etkileyebilmektedir. Howes vd., (2011) yaptıkları çalışmada okul öncesi öğretmenleri çocuklarla olan ilişkilerini düşük çatışma ve olumlu yakınlık derecesinde algıladıklarında, çocukların kayg1çekingenlik, saldırganlık ve akran şiddetine maruz kalma davranışlarında azalma olduğunu belirlemiştir. Sıcaklık ve yakınlık içeren öğretmen davranışları, olumlu bir sınıf atmosferinin oluşturulması ve çocuğun uygun sosyal davranışlar göstermesi ile ilişkili görülmektedir (Brophy-Herb vd., 2007). Okul öncesinde çocukların 
öğretmenleriyle kurdukları ilişkilerin kalitesi, hem içinde bulunan süreçte hem de ileriki eğitim yaşantılarında sosyo-duygusal ve davranışsal uyumlarını etkilemektedir (Birch ve Ladd, 1998; Pianta vd., 2005, Silver vd., 2005). Öğretmenleriyle olumlu yakın ilişki içinde olan çocukların ileriki okul yıllarında daha fazla olumlu sosyal davranışlar sergiledikleri, daha fazla sosyal becerilere sahip oldukları, bunun yanında saldırganlık davranışlarında azalma olduğu ve bu çocukların akademik alanda daha başarılı oldukları belirlenmiştir (Berry ve O'Connor, 2010; Hamre ve Pianta, 2001; Howes vd., 1994; Howes, 2000; Skalická, Belsky, Stenseng ve Wichstrøm 2015).

Öğretmenler çocukların yaşamında etkili bir rol modeldir. Öğretmen ve öğrenci arasındaki ilişki çocuğun gelişimini olumlu yönde destekleyebilir ya da ilişkide çatışma ve gerilimin kaynağ Çocukların ihtiyaçlarına duyarlı ilişkiler çocukların sosyal, duygusal ve davranışsal gelişimlerinde önemli olmaktadır. Çocuklarının olumsuz duygularına karşı duygu ifadesini kolaylaştıran, probleme ve duyguya odaklı olumlu tepkiler veren öğretmenlerin, çocuklarının duygu düzenleme ve duygu ifade etme becerilerinin gelişimine etkisi olduğu düşünülmektedir.

\section{Araştırmanın Amacı}

$\mathrm{Bu}$ araştırmada 5-6 yaş çocuklarının öğretmenleri ile olan ilişkilerinin, duygu düzenleme ve duygu ifade etme becerileri üzerindeki yordayıcı etkisini ortaya koymak amaçlanmıştır.

Bu amaç doğrultusunda aşağıdaki sorulara yanıt aranmıştır.

1. Öğretmen-öğrenci arasındaki ilişki düzeyi (çatışma/yakınlık) çocukların duygu düzenleme davranışlarını (değişkenlik/olumsuzluk, duygu düzenleme) anlamlı bir şekilde yordamakta midır?

2. Öğretmen-öğrenci arasındaki ilişki düzeyi (çatışma/yakınlık) çocukların duygu ifade etme davranışlarını anlamlı bir şekilde yordamakta midır? 


\section{Yöntem}

\section{Araştırma Modeli}

Okul öncesi çocukların öğretmenleri ile olan ilişkilerinin, çocukların duygu düzenleme ve duygu ifade etme davranışları üzerindeki etkisinin incelendiği bu araştırma ilişkisel tarama modeli çerçevesinde yürütülmüştür.

\section{Çalışma grubu}

Çalışma grubunu, İç Anadolu Bölgesinin bir ilinde MEB'e bağlı bağımsız anaokullarına ve anasınıflarında eğitim gören 146 çocuk ile 22 okul öncesi öğretmeni oluşturmaktadır. Çalışma grubu basit rastgele örnekleme yöntemi ile belirlenmiştir. Çocukların 75'i (\%51.3) kız,71'i (\%48.6) erkektir. Çocukların tamamı normal gelişim göstermektedir. Çalışmaya dahil olan öğretmenlerin, 2'si (\%9.0) 6-10 y1l, 5’i (\%22.7) 11-15 y1l, 13’ü (\%59.0) 16-20, 2’si (\%9.0) 21 ve üstü mesleki deneyime sahiptir. Çalışmadaki öğretmenlerin 1' i (\%4.5) 20-25 arası, 2'si (\%9.0) 26-30 arası, $4^{\prime}$ ü (\%18.1) 31-35 arası, 12' si (\%54.5) 36-40 arası, 3’ü (\%3.6) 41 ve üstü yaştadır. Okul türüne göre öğretmenlerin 16’s1 (\%72.7) bağımsız anaokulunda, 6’sı (\%27.3) anasınıfında çalışmaktadır. Örnekleme alınan okul öncesi öğretmenlerin tamamı kadındır. Öğretmenler en az lisans düzeyinde eğitim derecesine sahiptir.

\section{Veri Toplama Araçları}

Duygu Düzenleme Ölçeği: Shields and Cicchetti (1997) tarafindan geliştirilmiş, (Çorapçı Aksan diğ., 2010) tarafından Türkçeye uyarlanmıştır. Ölçek duygusal tepkiselliği ve duyguların ortamın koşullarına göre düzenlenip ifade edilmesini değerlendiren 24 ve Değişkenlik/olumsuzluk ve duygu düzenleme olmak üzere iki alt boyuttan oluşmaktadır. Değişkenlik/olumsuzluk alt boyutu; harekete geçme, tepkisellik, öfke kontrolü, huysuzluk ve esnek olmamaya yönelik maddelerden oluşmakta ve çocuktaki duygu durum değişkenliği ile olumsuz duygulanım gösterme eğilimini ölçmektedir (Örneğin; Duygu hali çok değişkendir; Kolaylıkla hayal kırıklığına uğrayıp sinirlenir). 
Duygu Düzenleme alt boyutu ise çocuğun duygularını ortama uygun olarak ifade etme becerisini ölçmektedir (Örneğin; Üzüldüğünü, kızıp öfkelendiğini veya korktuğunu söyleyebilir). 1 ile 4 arasında değişen Likert tipi bir ölçektir. Yağmurlu ve Altan (2010) ölçeğin iç tutarlılık katsayılarını anne değerlendirmelerinde .75 ve öğretmen değerlendirmelerinde .84 olarak belirlemiştir.

Duyguları Iffade Etme Testi: Yıldırım-Doğru (1999) tarafından geliştirilen test, duygu ile ilgili (Mutlu, üzgün, kızgın, şaşırmış) 3 soru olmak üzere toplam 12 maddeden oluşmaktadır. Ölçek Ergin (2003) tarafından tekrar uyarlanmıştır. Ölçek çocuklara bireysel olarak uygulanmaktadır. Test uygulanırken, maddelerin tümü çocuklara sorulmaktadır. Duygular belli bir düzende değil karışık olarak sıralanmaktadır. Her soru "1" puan olmak üzere toplam "12" puan üzerinden değerlendirme yapılmaktadır. Duygu ifade etme testi iç tutarlık katsayısının cronbach Alfa Tekniği'ne göre 0,82 olduğu belirlenmiştir (Ergin, 2003).

Öğretmen-Öğrenci İlişki Ölçeği (ÖÖIÖ): Pianta tarafında geliştirilmiş, öğretmenin bireysel olarak 4-8 yaş arası öğrencilerle olan ilişkilerini algılamalarını ölçen bir ölçme aracıdır. Ölçek 5'li Likert tipindedir. Kuramsal yaklaşıma dayalı olarak geliştirilen Ebeveyn - Çocuk İlişkisi Ölçeği'nin (Pianta, 1992) Türkiye'ye uyarlanmasında da üç boyutlu yapının çalışmadığı görülmüş ve ölçekten yedi madde çıkartılarak ölçek iki boyut olarak tanımlanmıştır (Akgün ve Yeşilyaprak, 2010). Görülmektedir ki; bu çalışmaya benzer şekilde başka çalışmalarda da çatışma, yakınlık ve bağımlılık boyutlarından oluştuğu ileri sürülen ilişki farklı örneklemlerde iki boyutlu olarak görülebilmektedir. Dolayısıla ölçeğin Türkçe formu iki boyuttan oluşmaktadır. Ölçeğin Türkiye uyarlaması 23 maddeden ve iki boyuttan oluşmaktadır. Güvenirlik çalışmaları kapsamında Cronbach Alfa katsayıları yakınlık alt boyutu için .83; çatışma alt boyutu için .86 olduğu tespit edilmiştir. Ölçeğin çatışma boyutundan alınan yüksek puan öğretmen-öğrenci ilişkisinde çatışmanın; yakınlık boyutundan alınan yüksek puan ise ilişkide yakınlığın varlığına işaret etmektedir. (Demirtaş Zorbaz, GençtanırımKurt, Özer ve Ergene, 2016). 


\section{Uygulama}

Öğretmen ve öğrenci kişisel bilgi formları, Duygu Düzenleme Ölçeği ve Öğrenci-Öğretmen İlişki Ölçeği okul öncesi öğretmenleri tarafından doldurulmuştur. Duygu İfade Etme Testi ise araştırmacı tarafından çocuklara bireysel olarak uygulanmıştır. Veri toplama süreci yaklaşık üç hafta sürmüştür. Veri toplama sürecinden önce öğretmenler, araştırma ve ölçekler hakkında bilgilendirilmişlerdir. Uygulama öncesinde örnekleme alınan anaokulunda ve anasınıflarındaki çocuk sayılarının farklılık göstermesi nedeniyle her öğretmenden sadece 5 çocuk için, Duygu Düzenleme Ölçeği ve Öğretmen-Öğrenci İlişki Ölçeğini doldurmaları istemiştir. Ölçeklerin değerlendirilmesi sonucunda dört çocuk için doldurulan ölçek değerlendirmeye alınmamıştır.

\section{Verilerin Analizi}

Araştırma değişkenlerinin aidiyetin sonucunu yordama düzeylerini analiz etmek için ise çok değişkenli regresyon analizinin İleriye Doğru Seçim Metodundan (Stepwiseselection) yararlanılmıştır. Analize geçilmeden önce varsayımların (uç değerler, normallik, doğrusallık, çoklu bağlantı ve otokorelasyon) karşılanıp karşılanmadığı sınanmıştır. Öncelikle uç değerlerin olup olmadığı incelenmiştir. Tek değişkenli uç değerlerin olup olmadığı z standart puanlar hesaplanarak bulunmuş ve 3 ile +3 arasında olmayan altı veri analizden çıkartılmıştır. Daha sonra çok değişkenli uç değerlerin olup olmadığı Mahalanobis uzaklıkları hesaplanarak belirlenmiş ve bir veri analizden çıkartılmıştır. Böylece toplam 146 veri ile çalışma yürütülmüştür. Normallik varsayımının karşılanıp karşılanmadığını belirlemek için ise çarpıklık ve basıklık değerleri incelenmiş, bu değerlerin -1 ile +1 arasında yer aldığı görülmüş ve verilerin normal dağılımdan aşırı sapma göstermediği belirlenmiştir. Otokorelasyonun olup olmadığını belirlemek için Durbin Watson değeri hesaplanmış ve bu değerlerin 1.962 ile 2.109 Arasında bulunmuştur. Bulunan değerler1.5 ile 2.5 arasında olduğu için otokorelasyon varsayımı karşılanmıştır. Çok değişkenli normallik ile yordayıcı (bağımsız) değişkenlerle bağımlı değişkenler arasındaki ilişkinin doğrusallık varsayımları saçılma grafiği ile incelenmiş ve bu varsayımların 
karşılandığı belirlenmiştir. Çoklu bağlantı probleminin olup olmadığını belirlemek amaciyla tolerans (1-R $\left.{ }^{2}\right)$ ve VIF (varyans büyütme faktörü) değerleri hesaplanmıştır. Tolerans değerleri 0.20 'den daha büyük ve VIF değerleri 10'dan daha küçük bulunmuş ve yordayıcı değişkenler arasında çoklu bağlantının olmadığı belirlenmiştir. Araştırmada, elde edilen verilerin analizinde SPSS 22 istatistik programından yararlanılmış ve anlamlılık düzeyi $\mathrm{p}=0.05$ kabul edilmiştir.

\section{Bulgular}

Tablo 1. Araştırmada ele alınan bağımsız değişkenler ile duygu düzenleme ve duygu ifade etme arasındaki ilişkiye ait korelâsyon analizi sonuçları

\begin{tabular}{|c|c|c|c|}
\hline & Olumsuzluk/değişkenlik & $\begin{array}{l}\text { Duygu } \\
\text { Düzenleme }\end{array}$ & $\begin{array}{l}\text { Duygu } \\
\text { İfade Etme }\end{array}$ \\
\hline Öğretmen Öğrenci İlişki & $.329^{* *}$ & $.183^{*}$ & .058 \\
\hline Ölçeği/Çatışma & & & \\
\hline $\begin{array}{l}\text { Öğretmen Öğrenci İlişki } \\
\text { Ölçeği/Yakınlık }\end{array}$ & -.156 & .129 & $.172^{*}$ \\
\hline Cinsiyet & $.262^{* *}$ & -.005 & -.003 \\
\hline
\end{tabular}

Tablo 1'de, öğretmen-öğrenci arasındaki çatışma düzeyi ile duygu düzenleme alt boyutlarından olumsuzluk/değişkenlik ve duygu düzenleme değişkenlerin arasında pozitif yönlü anlamlı bir ilişki olduğu görülmektedir $\quad(r=.329, \quad \mathrm{p}<0.01 ; \quad \mathrm{r}=183, \quad \mathrm{p}<0.05)$. Öğretmen-öğrenci arasındaki çatışma düzeyi ile duygu ifade etme değişkeni arasında anlamlı ilişki olmadığı görülmektedir. Öğretmen-öğrenci arasındaki yakınlık düzeyi ile duygu düzenleme alt boyutlarından olumsuzluk/değişkenlik ve duygu düzenleme değişkenlerin arasında anlamlı bir ilişki olmadığı ( $\mathrm{r}=-.156, \mathrm{p}>0.01 ; \mathrm{r}=.129$, $\mathrm{p}>0.01)$ öğretmenöğrenci arasındaki yakınlık düzeyi ile duygu ifade etme değişkeni arasında anlamlı bir ilişki olduğu görülmektedir ( $\mathrm{r}=.172, \mathrm{p}<0.05)$. Cinsiyet ile olumsuzluk/değişkenlik arasında pozitif yönlü bir ilişki olduğu ( $\mathrm{r}=.262, \mathrm{p}<0.01)$; duygu düzenleme ve duygu ifade etme değişkeni ile anlamlı ilişki olmadığı belirlenmiştir ( $r=--.005, p>0.01$; $\mathrm{r}=.003, \mathrm{p}>0.01$ ). 
Tablo 2. Öğretmen-öğrenci ilişkilerinin çocukların değişkenlik/olumsuzluk boyutunu yordamasına ilişkin çoklu regresyon analizi sonuçları

\begin{tabular}{|c|c|c|c|c|c|c|}
\hline Model & Öğretmer & renci İlişkisi & B & $\begin{array}{l}\text { Std. } \\
\text { Hata }_{B}\end{array}$ & B & $t$ \\
\hline \multirow[t]{7}{*}{ Değişkenlik/Olumsuzluk } & Sabit & & 18.126 & 1.928 & & $9.404^{* *}$ \\
\hline & Çatışma & & .379 & .091 & .329 & $4.185^{* *}$ \\
\hline & $\mathrm{R}=0.329$ & $\mathrm{R}^{2}=0.109$ & \multicolumn{2}{|c|}{$\mathrm{F}_{(1,144)}=17.512$} & \multicolumn{2}{|c|}{$\mathrm{p}=.000$} \\
\hline & Sabit & & 20.483 & 2.045 & & $10.016^{* *}$ \\
\hline & Çatışma & & .348 & .089 & .302 & $3.908^{* *}$ \\
\hline & Cinsiyet & & -3.052 & 1.045 & -.226 & $-2.921^{* *}$ \\
\hline & $\mathrm{R}=0.398$ & $R^{2}=0.159$ & \multicolumn{2}{|c|}{$F_{(2,143)}=13.481$} & \multicolumn{2}{|r|}{$\mathrm{p}=.000$} \\
\hline
\end{tabular}

${ }^{* *} p<0.01$

Tablo 2'ye göre, regresyon analizinin varyans analizi sonuçlarına göre kurulan modellerin tümü anlamlıdır ( $\mathrm{p}<.01)$. Birinci aşamada, öğretmenöğrenci ilişkilerinde yaşanan çatışma durumu değişkeni ile regresyon eşitliğine girilmiş ve bu değişkenin varyansın \%10.9'unu açıladığı görülmüştür $\quad\left(R=.329, \quad R^{2}=0.109\right)$. Diğer bir ifade ile değişkenlik/olumsuzluğun en güçlü yordayıcısı öğretmen-öğrenci ilişkilerindeki çatışma olarak tespit edilmiştir. Elde edilen beta değerinin pozitif $(+)$ olması, öğretmen- öğrenci ilişkilerinde yaşanan çatışma durumları artıkça çocukların değişkenlik ve olumsuzluk davranışlarının da arttığ göstermektedir.

İkinci aşamada çocuğun cinsiyet değişkeni modele eklenmiş ve bu değişkenin modele eklenmesi ile değişkenlik/olumsuzluk puanları \%15.9'a çıkmıştır ( $\left.R=.398, R^{2}=0.159\right)$. Yani, çocuğun cinsiyet değişkeninin açıklanan varyansa \%5.0'lık bir katkısı olduğu görülmektedir. Cinsiyet değişkeni ile değişkenlik/olumsuzluk alt boyutu arasındaki ilişkinin niteliği dikkate alındığında, beta değerinin negatif (-) yönlü olması, değişkenlik/olumsuzluk ile cinsiyet değişkeni arasında ters yönlü bir ilişki olduğunu göstermektedir. Bu sonuca göre kız çocukların değişken ve olumsuz davranışlarının daha az olduğu saptanmıştır $(\beta=-.226$; $\mathrm{p}<0.01)$.

Tablo 3 incelendiğinde, öğretmen-çocuk ilişkisinin duygu düzenlemeyi anlamlı düzeyde yordadığı görülmektedir $(\mathrm{p}<.05)$. Birinci aşamada, öğretmen öğrenci ilişkilerinde yaşanan çatışma durumu değişkeni ile regresyon eşitliğine girilmiş ve bu değişkenin varyansın \%19.7'sini açıkladığı görülmüştür $\left(R=.444, R^{2}=0.197\right)$. Diğer bir ifade ile duygu düzenlemenin en güçlü yordayıcısı öğretmen-öğrenci 
ilişkilerindeki çatışma olarak tespit edilmiştir. Elde edilen beta değerinin pozitif (+) olması, öğretmen ve öğrenci ilişkilerinde yaşanan çatışma durumları ile çocukların duygu düzenleme davranışları arasında pozitif yönlü bir ilişki olduğunu göstermektedir.

Tablo 3. Öğretmen-öğrenci ilişkilerinin çocuklarn duygu düzenleme boyutunu yordamasına ilişkin çoklu regresyon analizi sonuçları

\begin{tabular}{|c|c|c|c|c|c|c|}
\hline Model & Öğretme & ğrenci İlişkis & B & $\begin{array}{l}\text { Std. } \\
\text { Hata }_{B}\end{array}$ & B & $t$ \\
\hline \multirow{12}{*}{ Duygu Düzenleme } & Sabit & & 42.395 & 1.780 & & $23.821^{* *}$ \\
\hline & Çatışma & & .498 & .084 & .444 & $5.947^{* *}$ \\
\hline & $\mathrm{R}=0.444$ & $\mathrm{R}^{2}=0.197$ & $F_{(1,144)}=35.372$ & $\mathrm{p}=.000$ & & \\
\hline & Sabit & & 44.593 & 1.887 & & $23.630^{* *}$ \\
\hline & Çatışma & & .468 & .082 & .418 & $5.702^{* *}$ \\
\hline & Cinsiyet & & -2.845 & .964 & -.216 & $-2.951^{* *}$ \\
\hline & $R=0.493$ & $\mathrm{R}^{2}=0.243$ & $F_{(2,143)}=22.987$ & $7 \quad \mathrm{p}=.000$ & & \\
\hline & Sabit & & 28.378 & 5.593 & & $5.074^{* *}$ \\
\hline & Çatışma & & .598 & .090 & .533 & $6.622^{* *}$ \\
\hline & Yakınlık & & .302 & .099 & .259 & $3.069^{* *}$ \\
\hline & Cinsiyet & & -3.731 & .980 & -.284 & $-3.806^{* *}$ \\
\hline & $\mathrm{R}=0.539$ & $\mathrm{R}^{2}=0.290$ & $F_{(3,142)}=19.366$ & $\mathrm{p}=.000$ & & \\
\hline
\end{tabular}

${ }^{* *} p<0.01 \quad{ }^{*} p<0.05$

İkinci aşamada çocuğun cinsiyet değişkeni modele eklenmiş ve bu değişkenin modele eklenmesi ile değişkenlik/olumsuzluk puanları \%24.3'e çıkmıştır ( $\left.\mathrm{R}=.493, \mathrm{R}^{2}=0.094\right)$. Yani, çocuğun cinsiyet değişkeninin açıklanan varyansa \% $4.6^{\prime}$ lık bir katkısı olduğu görülmektedir.

Üçüncü aşamada yakınlık değişkeni modele eklendiğinde ise üç değişken duygu düzenleme puanları ile orta düzeyde bir ilişki vererek puanlardaki varyansın \%29,0' unu açıklamaktadır ( $\left.\mathrm{R}=.539, \mathrm{R}^{2}=0.290\right)$. Bu sonuçlar incelendiğinde, yordayıcı değişkenlerin duygu düzenleme puanları üzerindeki etkileri bakımından en güçlü ve anlamlı yordayıcının çatışma, ikinci güçlü ve anlamlı yordayıcının cinsiyet, üçüncü güçlü ve anlamlı yordayıcının ise yakınlık değişkeni olduğu belirlenmiştir ( $\mathrm{p}<.05)$. Cinsiyet değişkeni ile duygu düzenleme alt boyutu arasındaki ilişkinin niteliği dikkate alındığında, beta değerinin negatif (-) yönlü olması, duygu düzenleme ile cinsiyet değişkeni arasında ters yönlü bir ilişki olduğunu göstermektedir. Erkek öğrencilerin duygu düzenleme puanlarının ise kız öğrencilerden 0.284 daha yüksek olduğu belirlenmiştir $(\beta=-.284 ; \mathrm{p}<0.01)$. Bu sonuca göre kız çocukların değişken 
ve olumsuz davranışlarının daha az olduğu saptanmıştır. $(\beta=.226$; $\mathrm{p}<0.01)$.

Tablo 4. Öğretmen-öğrenci ilişkilerinin çocukların duygu ifade etme boyutunu yordamasına ilişkin çoklu regresyon analizi sonuçları

\begin{tabular}{|c|c|c|c|c|c|}
\hline Model & Öğretmen-Öğrenci İlişkisi & B & $\begin{array}{c}\text { Std. } \\
\text { Hata }_{B} \\
\end{array}$ & $\beta$ & $t$ \\
\hline \multirow[t]{7}{*}{ Duygu İfade Etme } & Sabit & 24.269 & 1.128 & & $21.516^{* *}$ \\
\hline & Çatışma & .118 & .053 & .183 & $2.233^{*}$ \\
\hline & $\mathrm{R}^{2}=0.033$ & \multicolumn{3}{|c|}{$\mathrm{F}_{(1,144)}=4.986 \quad \mathrm{p}=.027$} & \\
\hline & Sabit & 13.665 & 3.593 & & $3.803^{* *}$ \\
\hline & Çatışma & .205 & .059 & .317 & $3.502^{* *}$ \\
\hline & Yakınlık & .190 & .061 & .281 & $3.099^{* *}$ \\
\hline & $\mathrm{R}^{2}=0.094$ & \multicolumn{3}{|c|}{$F_{(2,143)}=7.444$} & \\
\hline
\end{tabular}

${ }^{* *} p<0.0 \quad{ }^{*} p<0.05$

Birinci aşamada; belirlenen bu değişkenlerden en yüksek katkısı olan öğretmen öğrenci ilişkilerinde yaşanan çatışma durumu değişkeni ile regresyon eşitliğine girilmiş ve bu değişkenin varyansın \%3.3'ünü açıladığ1 görülmüştür $\left(R=.183, R^{2}=0.033\right)$. Elde edilen beta değerinin pozitif $(+)$ olması, öğretmen-öğrenci ilişkilerinde yaşanan çatışma durumları ile çocukların duygu ifade etme davranışları arasında pozitif yönlü bir ilişki olduğunu göstermektedir.

İkinci aşamada yakınlık değişkeni modele eklenmiş ve bu değişkenin modele eklenmesi ile duygu ifade etme puanları \%9.4'e çıkmıştır $(R=.307$, $\mathrm{R}^{2}=0.094$ ). Elde edilen beta değerinin pozitif (+) olması, öğretmenöğrenci ilişkilerinde yaşanan yakınlı durumları arttıkça çocukların duygu ifade etme davranışlarının arttığını göstermektedir. Bu sonuca göre yordayıcı değişkenlerin duygu ifade etme puanları üzerindeki etkileri bakımından en güçlü ve anlamlı yordayıcının çatışma, ikinci güçlü ve anlamlı yordayıcının ise yakınlık değişkeni olduğu belirlenmiştir $(\mathrm{p}<.05)$.

\section{Tartışma ve Sonuç}

Araştırmada elde edilen bulgulara göre öğretmen-öğrenci ilişkisinin çatışma boyutu değişkenlik/olumsuzluk alt boyutunda pozitif yönlü; cinsiyet değişkeni ise negatif yönlü bir ilişkiye sahiptir. Bu sonuca göre, öğretmen ve öğrenci ilişkilerinde yaşanan çatışma durumu arttıkça 
çocukların değişken ve olumsuz davranışlarının arttığ1; kız çocukların değişken ve olumsuz davranışları gösterme durumlarının erkeklere göre daha az olduğu saptanmıştır. Konu ile ilgili alan yazında, öğretmenöğrenci arasındaki ilişkinin kalitesinin, çocuklarda olumlu sosyal davranışlarının artmasında, olumsuz davranışların azalmasında ve akran grupları arasında olumlu sosyal davranışlar sergilenmesinde önemli rolü olduğu vurgulanmaktadır (Hoşgörür, 2012; Hughes, Cavell ve Jackson, 1999). Öğretmen ve öğrenci arasındaki çatışmalı durumlar çocuğun sosyal ilişkilerde olumlu örnekleri görmesini engelleyerek, çocukların prososyal davranma ve ilişkileri sürdürmede gerekli olan sosyal becerileri kazanmasını zorlaştırmakta (Zimmer-Gembeck, Geiger ve Crick, 2005) bu durumda çocuklarda istenmeyen davranışlar ortaya çıkabilmektedir (Doumen, Verschueren ve Buyse, 2009; Runions, Vitaro, Cross ve Boivin, 2014; Stipek ve Miles, 2008). Öğretmen-öğrenci arasındaki ilişki sıcak, cevaplayıcı ve sevecen bir tutum sergilemelidir. $\mathrm{Bu}$ durum çocukların kendilerini güvende hissetmelerini ve ilişkiye yönelik olumlu algıları sonucunda olumlu davranışlar göstermelerini sağlayabilir. Konu ile ilgili alan yazında öğretmen-öğrenci arasında kurulan nitelikli ilişkilerin ve çocuğun zihninde bu ilişkilere yönelik oluşturduğu olumlu atıfların, olumlu tutum ve davranışların sergilenmesinde etkili olduğu belirtilmektedir (Baker, 2006; Beyazkürk ve Kesner, 2005; Hamre ve Pianta, 2005; Murray ve Greenberg, 2000; Pianta vd., 1997; White, 2007).

Araştırmada ele alınan cinsiyet değişkeninin çocukların değişken ve olumsuz davranışlarını önemli derecede yordadığı, buna göre erkek çocukların kız çocuklarına göre daha fazla değişken ve olumsuz davranışlar gösterdikleri saptanmıştır. Konu ile ilgili alan yazın incelendiğinde kızların olumsuz duygusal stratejileri daha az kullandıklarını (Eisenberg vd., 1993) erkeklere göre daha fazla olumlu sosyal davranış sergilediklerini ortaya koyan pek çok çalışmaya rastlanmaktadır (Gülay, 2008; Hay ve Cook, 2007; Karaaslan, 2012; Knafo ve Plomin, 2006; Yaralı ve Özkan, 2016).

Elde edilen bulgulara göre öğretmen-öğrenci ilişkisinin çatışma ve yakınlık boyutu duygu düzenleme alt boyutunda pozitif yönlü bir ilişkiye sahiptir. Öğretmen ve çocuk ilişkileri çocukların gelişiminde önemli etkiye sahiptir. Bu ilişkiler çocuğun gelişimini destekleyebilir ya 
da ilişkide çatışma kaynağı olabilir. Öğretmen öğrenci ilişkisinde çatışma alt boyutu puanları çocuğun öğretmen tarafından olumsuz algılanan davranışlarını, duygusal boyuttaki olumsuz etkileşimlerini, davranışların etkili biçimde yönetilememesini kapsamaktadır. Yüksek çatışma puanları öğretmenin çocukla yaşanan olası anlaşmazlıklara, duygusal olarak o çocukla nasıl baş edebileceğini bilememeye ve kendini o ilişki içinde etkili olarak tanımlayamamayı belirtmektedir (Şahin, 2014). Öğretmen ve çocuk arasında yaşanan çatışmalar öğretmenin çocuğun istenmeyen davranışlarına odaklanmasına, çocuğun anlaşılmadığını düşünmesine, sınıfta kendini tehdit altında hissetmesine yol açabilir (Webster-Stratton, 1999; Webster-Stratton ve Reid, 2004; Webster-Stratton, Reid and Stoolmiller, 2008). Olumsuz öğretmen davranışları da çocuklarda olumlu davranışlar oluşturmayacağı gibi başka olumsuz davranışların oluşmasına da sebep olabilir (ÖnderKülahoğlu, 2000). Bu durum öğretmen çocuk ilişkisinde çatışma boyutunun duygu düzenlemeyi pozitif yönde yordamasının nedeni olabilir. Howes, (2000) ve Pianta ve Nimetz, (1991) öğretmen-çocuk ilişkisinin çocuğun dışa ve içe yönelik davranış problemleriyle ilişkili olabildiğini ifade etmişlerdir (Durmuşoğlu-Saltalı, 2013; Hughes, Bullock ve Coplan, 2014). Nitelikli öğretmen-öğrenci ilişkisi, çocuklarda kendi duygularını anlamaları ve ilgilerine odaklanmaları konusunda büyük destek sağlamaktadır (Ertürk, 2013; Howes ve Hamilton, 1992; Kuyucu, 2012; Tok, 2011). Konu ile ilgili pek çok çalışmada, çocukların öğretmenleriyle kurdukları ilişkiyi algılama biçimleri ile ilişkiye yönelik davranışları arasında bir bağ olduğu, çocukların öğretmenleri ile kurdukları ilişkiyi algılama biçimlerinin, davranışlarına yansıdığı belirlenmiştir (Birch ve Ladd, 1998; Howes, Hamilton ve Matheson, 1994; Murray ve Greenberg, 2000; Tok, 2011). Öğretmen-çocuk ilişkisinde yakınlık boyutunun hakim alması çocuğun sosyal ilişkilerde olumlu örnekleri görmesine, öğretmenin de olumlu davranışlara destek olarak duygu düzenleme davranışlarının pekişmesine, böylece öğretmen-çocuk ilişkisinin yakınlık boyutu çocukların duygu düzenleme puanlarının artmasına katkı sağlamış olabilir. Elde edilen diğer bir bulgu duygu düzenleme ile cinsiyet değişkeni arasında ters yönlü bir ilişki olduğunu göstermektedir. Erkek öğrencilerin duygu düzenleme puanlarının kız öğrencilere göre daha yüksek olduğu belirlenmiştir. Duygu düzenleme 
ile ilgili literatürde $\mathrm{klz}$ ve erkek çocukların farklı sosyalizasyonlar sebebiyle farklı duygu düzenleme becerileri gösterebildiği görülmektedir (Altan, 2006; Eisenberg, Cumberland ve Spinrad, 1998; Saarni, 1984). Cinsiyet temelli yaşanan bu farklılığın çocuğun cinsiyetine göre sahip olduğu duygusal özelliklerden (Bajgar, Ciarrochi, Lane ve Deane, 2005, Hughes ve Dunn, 2002) kaynaklanabileceği düşünülmektedir.

Öğretmen-öğrenci ilişkisinin çatışma ve yakınlık boyutu duygu ifade etmede pozitif yönlü yordayıcı etkiye sahiptir. Yaşamın ve gelişimin tüm alanlarındaki şekillenme sürecinde temel bir rol üstlenen okul öncesi dönemde çocukların deneyimledikleri olumlu duygularını ifade edebildikleri gibi, olumsuz duygularını da yıkıcı olmayan, diğerlerine zarar vermeyi hedeflemeyen bir şekilde ifade edebilmeyi öğrenmeleri oldukça önemlidir (Aydın, 2014; Durmuşoğlu-Saltalı ve Deniz, 2010). Yakınlık, sıcaklık derecesini kapsar ve öğretmen ile öğrenci arasında var olan açık iletişim ve destek işlevi görür. Çocuk ile sıcak bir duygusal bağ kurmak olumlu etki ve tutumları kolaylaştırabilir. Çatışmalı öğretmenöğrenci ilişkileri uyumsuz etkileşimler ve aralarında uyumsuzluk ile ilişkilidir. Öğretmen-çocuk ilişkisinde yakınlık gösteren öğretmenin çocukla gerektiği kadar ilgilenerek, sorularına cevaplayıcı olarak, olumlu duygusal etkileşimler içinde bulunarak ve olumlu davranışları ile çocuklara model olarak, çocukların da benzer davranışları sergilemelerine katkı sağlayabilir.

\section{Öneriler}

Öğretmen-öğrenci ilişkisinin çocukların duygu düzenleme ve duygu ifade etmede önemli etken olduğu bulunmuştur. Alan yazın incelendiğinde ülkemizde okul öncesi dönemde duygu düzenleme ve duygu ifade etmeye yönelik çalışmalar yeterli düzeyde değildir. İstenen düzeye ulaşması açısından araştırmacılar tarafından duygu düzenleme ve duygu ifade etme kavramı, farklı değişkenlerle bir arada ele alınıp incelenebilir. Öğretmen-öğrenci ilişkisini etkileyen faktörleri incelemeye (anneye bağlanma biçimi, bireyin akademik başarı, sosyal beceriler, kişilik gelişimi) yönelik araştırmalar planlanabilir. 
EXTENDED ABSTRACT

\title{
Examination of the Effect of Teacher-Student Relationship on Students Emotion Regulation and Emotion Expression Skills
}

\author{
Belgin Liman \\ Niğde Ömer Halisdemir University
}

The ways in which children express their positive or negative emotions may differ depending on their experiences. Expressing emotion is a way of conveying children's emotions to their surroundings (Denham, 2006) and behaviors performed by using facial, voice and other body movements are used in conveying their emotional states (Chaplin, 2015). Emotional reactions that occur during emotion expression that affect behaviors are defined as emotion regulation (Bridges, Denhama, and Ganiban, 2004). Emotion regulation is the control system of emotions experienced and expressed by children (Cole, Martin, and Dennis, 2004). Children encounter many situations requiring regulation of their emotions during their elementary school experiences (Denham, 2006), and this affects their behavioral, academic and social skills. For successful emotion regulation, children need to learn to understand and send positive emotion messages in their interpersonal relationships and positive school experiences (Halberstadt, Denham, and Dunsmore, 2001).

From the moment the child is born, the influence of the family on all developmental areas, including the ability to regulate emotions, is significant (Duncan and Brooks-Gunn, 2000; Linver, Brooks-Gunn, and Kohen, 2002; Morris, Silk, Steinberg, Myers, and Robinson, 2007). The bond established between parents and their children is important for the healthy development and social adaptation of children. The teacher is one of the people with whom the kindergarten children form a relationship and secure bond after their parents (Koles, O'Connor and McCartney, 2009; Zhang, 2011; Zhang and Nurmi, 2012). Just as the attachment between parents and children is of great importance for the emotional development of children, the relationship based on mutual 
trust between the teacher and the children is also indispensable for the emotional development of children.

Some teacher-student relationships involve closeness and emotion, while others may involve conflict and tension. Forming strong and supportive relationships with their teachers allows children to feel more confident and competent in the school environment in order to establish more positive relationships with their peers, and to have positive academic outcomes (Birch and Ladd, 1997; Curby, Rimm-Kaufman, and Pointz, 2009; Hamre and Pianta, 2006; Peisner-Feinberg et al., 2001; Wentzel, 2009). Teachers' supportive behaviors and low conflict situations are associated with high academic achievement (Dobbs and Arnold, 2009; Hamre and Pianta, 2001; Ly, Zhou, Chu, and Chen, 2012; Silver, Measelle, Armstrong, and Essex, 2005; Zimmer-Gembeck and Connell, 1998). Negative relationships negatively affect the development of children (Doumen, Verschueren, Buyse, Germeijs, Luyckx, and Soenens, 2008; Howes, 2000; Pianta and Nimetz, 1991). Kindergarten children who develop secure bonds with their teachers are less likely to show irregular anger and behavioral problems, and they are more likely to display positive emotions at school (DeMulder, Denham, and Schmidt, 2000; Mitchell-Copeland, Denham, and DeMulder, 1997). As the quality of teacher-student relationship increases, students with problem behaviors display more positive social, behavioral and adaptation changes (Decker, Dona, and Christenson, 2007). The relationship between teachers and students may affect not only students but also the emotional-social state of the teachers.

Relationships that are sensitive to the needs of children are important in the social, emotional and behavioral development of children. Teachers who facilitate emotion expression when faced with children's negative emotions and who give positive reactions to the problems and emotions are believed to have an effect on the development of children's emotion regulation and emotion expression skills. The purpose of the present study was to explore the predictive effect of the relationships of 5-6 years old children with their teachers on their emotion regulation and emotion expression skills.

Selected by simple random sampling method, the study group was made up of 146 children and 22 kindergarten teachers who had been 
attending and working at independent kindergartens and kindergartens affiliated with the Ministry of National Education in a city in the Central Anatolia Region during the 2019-2020 academic year. The Personal Information Form, Emotion Regulation Q-Scale, Emotion Expression Scale and Teacher-Student Relationship Scale were used in the study. The forward selection method of the multivariate regression analysis (Stepwise regression) was employed to analyze the predictive levels of the study variables on the outcome of belonging.

The conflict dimension of the teacher-student relationship and the gender variable significantly predicted the variability/negativity scores. In the variability/negativity sub-dimension, the conflict dimension of teacher-student relationship had positive relationship, whereas the gender variable had negative relationship. In terms of its effects on emotion regulation scores, the strongest and most significant predictor was conflict. This was followed by gender and closeness, respectively. Finally, the conflict and closeness dimension of the teacher-student relationship had a positive predictive effect in the emotion regulation and emotion expression sub-dimension.

\section{Kaynakça / References}

Altan, Ö. (2006). The effects of maternal socialization and temperament on children's emotion regulation (Unpuplished Master's Thesis). Koç University, İstanbul.

Aydın, İ. S. (2014). Öğretmenlerin sınıfta kullandığı sözel dil üzerine öğrenci görüşlerinin değerlendirilmesi. Buca Eğitim Fakültesi Dergisi, 37, 4557.

Bajgar, J., Ciarrochi, J., Lane, R., and Deane, F. P. (2005). Development of the levels of emotional aware nesss cale for children (LEAS-C). British Journal of Developmental Psychology, 23(4), 569-586.

Berry, D., and O'Connor, E. (2010). Behavioral risk, teacher-child relationships, and social skill development across middle childhood: A child-by environment analysis of change. Journal of Applied Developmental Psychology, 31, 1-14. 
Beyazkürk, D. ve Kesner, J. (2005). Teacher-student relationship in turkis hand united state schools: A cross-cultural study. International Education Journal, 6(5), 547-554.

Birch, S. H. and Ladd, G.W. (1997). The teacher-child relationship and children'searly school adjustment. Journal of School Pyschology, 35(1), 61-79.

Birch, S. H. and Ladd, G. W. (1998). Interpersonal behaviors in children and teacher-child relationship. Developmental Psychology, 34, 934-946.

Bridges, L. J., Denham, S. A. and Ganiban, J. M. (2004). Definitional issues in emotion regulation. Child Development, 75, 340-345.

Brophy-Herb, H. E. Lee, R. E., Nievar, M. A., and Stollak, G. (2007). Preschoolers' social competence: Relations to family characteristics, teacher behaviors and classroom climate. Journal of Applied Developmental Psychology, 28(2), 134-148.

Büyüköztürk, Ş. (2011). Sosyal Bilimler için veri analizi el kitabı: İstatistik, araştırma deseni, SPSS uygulamaları ve yorum (14. Baskı). Ankara: Pegem Akademi.

Cole, P. M., Martin, S. E. and Dennis, T. A. (2004). Emotion regulation as a scientific construct: Methodological challenges and directions for child development research. Child development, 75(2), 317-333.

Curby, T. W., Rimm-Kaufman, S. E. and Ponitz, C. C. (2009). Teacher-child interactions and children's achievement trajectories across kindergarten and first grade. Journal of Educational Psychology, 101(4), 912.

Çorapçı, F., Aksan, N., Arslan-Yalçın, D. ve Yağmurlu, B. (2010). Okul öncesi dönemde duygusal, davranışsal ve sosyal uyum taraması: Sosyal yetkinlik ve davranış değerlendirme-30 ölçeği. Çocuk ve Ergen Ruh Sağlığı Dergisi, 17, 3-14.

Decker, D. M., Dona, D. P. and Christenson, S. L. (2007). Behaviorally at-risk African American students: The importance of student-teacher relationships for student outcomes. Journal of School Psychology, 45(1), 83-109.

Demirtaş Zorbaz, S., Gençtanırım-Kurt, D., Özer, A. ve Ergene, T. (2016). Öğretmen - Öğrenci İlişki Ölçeği'nin (ÖÖIÖ) uyarlanması. Eğitimde ve Psikolojide Ölçme ve Değerlendirme Dergisi, 7(2), 407-418. 
DeMulder, E. K., Denham, S. and Schmidt, M. (2000). Q-sort assessment of attachment security during the preschool years: Links from home to school. Developmental Psychology, 36, 274-282.

Denham, S. A. (2006). Social-emotionalcompetence as support for school readiness: What is it and how do weassess it? Early Education and Development, 17, 57-89.

Doumen, S., Verschueren, K., Buyse, E., Germeijs, V., Luyckx, K., and Soenens, B. (2008). Reciprocal relations between teacher-child conflict and aggressive behavior in kindergarten: A three-wave longitudinal study. Journal of Clinical Child and Adolescent Psychology, $37,588-599$.

Duncan, G. J. and Brooks-Gunn, J. (2000). Family poverty, welfare reform and child development. Child development, 71(1), 188-196.

Durmuşoğlu-Saltalı, N. and Deniz, M. E. (2010). Duygu Eğitimi Programı'nın okul öncesi eğitime devam eden altı yaş çocuklarının duygusal becerilerine etkisi. Kuram ve Uygulamada Eğitim Bilimleri, 10(4), 2105-21-40.

Durmuşoğlu-Saltall, N. (2013). The teacher student relationship As a predictor of preschoolerse social anxiety. Mevlana International Journal of Education, 3(4), 118-126.

Eisenberg, N., Fabes, R. A., Bernzweig, J., Karbon, M., Poulin, R. and Hanish, L. (1993). The relations of emotionality and regulation to preschoolers' social skills and sociometric status. Child development, 64(5), 1418-1438.

Eisenberg, N., Cumberland, A. and Spinrad, T. L. (1998). Parental socialization of emotion. Psychological Inquiry, 9(4), 241-273.

Eisenberg, N., Valiente, C., Fabes, R. A., Smith, C. L., Reiser, M., Shepard, S. A., Losoya, S. H., Guthrie, I. K., Murphy, B. C. and Cumberland, A. J. (2003). The relations of effortful control and ego control to children's resiliency and social functioning. Developmental Psychology, 39(4), 761-776.

Ergin, H. (2000). Illetişim becerileri eğitim programinin okulöncesi dönem çocuklarının iletişim becerileri düzeyine etkisi. Yayınlanmamış DoktoraTezi, İstanbul Üniversitesi, İstanbul.

Ertürk, H. G. (2013). Öğretmen çocuk etkileşiminin niteliği ile çocukların öz düzenleme becerisi arasındaki ilişkinin incelenmesi. Yüksek Lisans Tezi. Hacettepe Üniversitesi, Ankara. 
Gülay, H. (2008). 5-6 yaş çocuklarına yönelik akran ilişkileri ölçeklerinin geçerlik güvenirlik çalışmalar ve akran ilişkilerinin çeşitli değiş̧kenler açısından incelenmesi. Doktora Tezi. Marmara Üniversitesi Eğitim Bilimleri Enstitüsü, İstanbul.

Hamre, B. K. and Pianta, R. C. (2001). Early teacher-child relationships and the trajectory of children's school out comes through eight grade. Child Development, 72(2), 625-638.

Hamre, B. K. and Pianta, R. C. (2005). Can instructional and emotional support in the first-grade classroom make a difference for children at risk of school failure? Child Development, 76(5), 949-967.

Hamre, B. K. and Pianta, R. C. (2006). Student-Teacher Relationships. In G. G. Bear and K. M. Minke (Eds.), Children's needs III: Development, prevention, and intervention (p.59-71). Washington, DC, US: National Association of School Psychologists.

Hay, D. E. and Cook, K. V. (2007). The transformation of prosocial behavior from infancy to childhood. C. A. Brownwll ve C. B. Kopp (Eds.), Socioemotional Development In The Toddler Years: Transitions and transformations (p.100-131). NY: Guilford Press.

Helmsen, J. Koglin, U., and Petermann, F. (2012). Emotion regulation and aggressive behavior in preschoolers: The mediating role of social information processing. Child Psychiatry and Human Development, 43(1), 87-101.

Hoşgörür, V. (2012). İletişim. Z. Kaya (Ed.), Sinıf yönetimi (s.149-179). Ankara: Pegem Akademi.

Howes, C. and Hamilton, C. E. (1992). Children's relationships with childcare teachers: Stability and concordance with parental attachments. Child Development, 63, 867-878.

Howes, C. Hamilton, C. E., and Matheson, C. C. (1994). Children's relationships with peers: differential associations with aspects of the teacher-child relationship. Child Development, 65(1), 253-263.

Howes, C. (2000). Social-emonitonal classroom climate in childcare, child teacher relationship and children second grade peer relation. Social Development, 9(2), 191-204.

Howes, C., Guerra, A. W., Flugni, A., Zucker, E., Lee, L., Obregon, N. B. and Spivak, A. (2011). Classroom dimensions predict early peer interaction when children are diverse in ethnicity, race, and home language. Early Childhood Research Quarterly, 26(4), 399-408. 
Hughes, C. and Dunn, J. (1998). Understanding mind and emotion: Longitudinal associations with mental-state talk between young friends. Developmental Psychology, 34, 1026-1037.

Hughes, J. N., Cavell, T. A. and Jackson, T. (1999). Influence of the teacher student relationship on childhood conduct problems: a prospective study. Journal Of Clinical Child Psychology, 28(2), 173-184.

Hughes, K., Bullock, A. and Coplan, R.J. (2014). A person-centred analysis of teacher-child relationships in early childhood. British Journal of Educational Psychology, 84, 253-267.

Karaaslan, Ü. K. (2012). Okul öncesi eğitimin ve diğer değişkenlerin ilköğretim 1. stnıf ögrrencilerini duygular tanıma ve ifade etme becerilerine etkisi. Selçuk Üniversitesi Sosyal Bilimler Enstitüsü, Konya.

Knafo, A. and Plomin, R. (2006). Prosocial behavior from early to middle childhood: Genetic and environmental influences on stability and change. Developmental Psychology, 42(5), 771-786.

Kayhan-Aktürk, Ş. (2015). Okul öncesi dönem çocuklarında duygu düzenleme becerileri ile akran ilişkilerinin incelenmesi. Yüksek Lisans Tezi. İstanbul Üniversitesi, İstanbul.

Koles, B., O'Connor, E. and Mccartney, K. (2009). Teacher-child relationships in prekindergarten: The influence of child and teacher characteristics. Journal of Early Childhood Teacher Education, 30(1), 321.

Kuyucu, Y. (2012). Duyguları anlama becerileri farkh düzeydeki çocukların (60-72 ay) akranlarına karşı gösterdikleri duygusal ve davranışsal tepkilerin incelenmesi. Yayımlanmamış Yüksek Lisans Tezi. Selçuk Üniversitesi, Sosyal Bilimler Enstitüsü, Konya.

Linver, M. R., Brooks-Gunn, J. and Kohen, D. E. (2002). Family processes as pathways from in come to young children's development. Developmental psychology, 38(5), 719-734.

Ly, J., Zhou, Q., Chu, K. and Chen, S. H. (2012). Teacher-child relationship quality and academic achievement of chinese american children in immigrant families. Journal of School Psychology, 50, 535-553.

Miller, A. L. Fine, S. E. Gouley, K. K. Seifer, R. Dickstein, S. and Shields, A. (2006). Showing and telling about emotions: interrelations between facets of emotional competence and associations with classroom adjustment in head start preschoolers. Cognition and Emotion, 20(8), 1170-1192. 
Mitchell-Copeland, J., Denham, S. A. and DeMulder, E. K. (1997). Q-sort assessment of child teacher attachment relationships and social competence in the preschool. Early Education and Development, 8, 2739.

Morris, A. S., Silk, J. S., Steinberg, L., Myers, S. S. and Robinson, L. R. (2007). The role of the family context in the development of emotion regulation. Social Development, 16(2), 361-388.

Murray, C. and Greenberg, M. T. (2000). Children's relation-ships with teachers and bonds with schools: An investigation of patterns and correlates in middle childhood. Psychology in the Schools, 38, 425-446.

Önder-Külahoğlu, Ş. (2000). Öğrenci Davranışlarını etkileyen psikolojik ve sosyal faktörler. (Editör: L. Küçükahmet). Sinıf Yönetiminde Yeni Yaklaşımlar. Ankara: Nobel yayıncılık

Peisner-Feinberg, E. S., Burchinal, M. R., Clifford, R. M., Culkin, M. L., Howes, C., Kagan, S. L. and Yazejian, N. (2001). The relation of preschool child-care quality to children's cognitive and social developmental trajectories through second grade. Child Development, 72(5), 1534-1553.

Pianta, R. C. and Nimetz, S. L. (1991). Relationships between children and teachers: Associations with classroom and home behavior. Journal of Applied Developmental Psychology, 12(3), 379-393.

Pianta, R. C., Nimetz, S. L. and Bennett, E. (1997). Mother-child relationships, teacher-child relationships, and school out comes in preschool and kindergarten. Early Childhood Research Quarterly, 12, 263-280.

Pianta, R. C. and Stuhlman, M. W. (2004). Teacher-child relationships and children's success in the first years of school. School Psychology Review, 33(3), 444-458.

Romanchych, E. L. (2014). Young children's aggression: links between emotion regulation, other-child shared affect, parenting practices and parenting support. (Master Thesis). University of Windsor Master of Arts Windsor, Ontario, Canada.

Runions, K. C., Vitaro, F., Cross, D. and Boivin, M. (2014). Teacher-child relationship, parenting, and grow thin likelihood and severity of physical aggression in the early school years. Merrill-Palmer Quarterly, 60 (3), 274-301. 
Saarni, C. (2001). Cognition, context and goals: Significant components in social-emotional effectiveness. Social Development, 10(1), 125-127.

Silver, R. B., Measelle, J. R., Armstrong, J. M. and Essex, M. J. (2005). Trajectories of classroom externalizing behavior: Contributions of child characteristics, family characteristics, and the teacher-child relationship during the school transition. Journal of School Psychology, $43,39-60$.

Skalická, V., Belsky, J., Stenseng, F. and Wichstrøm, L. (2015). Reciprocal Relations Between Student-Teacher Relationship and Children's Behavioral Problems: Moderation by Child-Care Group Size, Child Development, 86(5), 1557-1570.

Stipek, D. and Miles, S. (2008). Effect of aggression on achievement: Does conflict with the teacher make it worse. Child Development, 79(6), 1721-1735.

Şahin, D. (2014). Öğrenci-öğretmen ilişki ölçeği'nin Türkçeye uyarlanması. Eğitim Bilimleri ve Uygulama, 13(25), 87-102.

Tok, M. (2011). Okul öncesi dönem çocuklarının ve öğretmenlerinin aralarındaki ılişkiyi algılama biçimlerinin davranışlarına olan yansımalarının incelenmesi. Yüksek Lisans Tezi, Sosyal Bilimler Enstitüsü, Ege Üniversitesi, İzmir.

Webster-Stratton, C. (1999). How to promote children's social and emotional competence. London: Paul Chapman.

Webster-Stratton, C. and Reid, M. J. (2004). Strengthening social and emotional competence in young children the foundation for early school readiness and success. Infants and Young Children, 17(2), 96113.

Webster-Stratton, C., Reid M. J. and Stoolmiller, M. (2008). Preventing conduct problems and improving school readiness: evaluation of the Incredible Years teacher and child training programs in high-risk schools. Journal of Child Psychology and Psychiatry, 49(5), 471-488.

Wentzel, K. (2009). Students' relationships with teachers as motivation contexts. In K. Wentzel A. Wigfield (Eds.), Handbook of motivation in school (p.301-322). Malwah, NJ: Erlbaum.

Yaralı, K. T. and Özkan H. K. (2016). Çocukların (60-72 aylık) sosyal problem çözme becerileri ile sosyal yetkinlik ve davranış durumları arasındaki ilişkinin incelenmesi. Türkiye Sosyal Araştırmalar Dergisi, 20(2), 345-361. 
Zhang, X. (2011). Parent and child and teacher-child relationships in Chinese preschoolers: The moderating role of preschool experience sand the mediating role of social competence. Early Childhood Research Quarterly, 26, 192-204.

Zhang, X. and Nurm1, J. E. (2012). Teacher-child relationship and social competence: a two-year longitudinal study of chinese preschoolers. Journal of Applied Developmental Psychology, 33(3), 125- 135.

Zimmer-Gembeck, M. J., Geiger, T. C. and Crick, N. R. (2005). Relational and physical aggression, prosocial behavior, and peer relations gender moderation and bidirectional associations. Journal of Early Adolescence, 25(4), 421-452.

\section{Kaynakça Bilgisi / Citation Information}

Liman, B. (2021). Öğretmen-Öğrenci İlişkisinin Öğrencilerin Duygu Düzenleme ve Duygu İfade Etme Becerilerine Etkisinin İncelenmesi. OPUS-Uluslararası Toplum Araştırmaları Dergisi, 18(39), 702-726. DOI: 10.26466/opus.839272. 